\title{
BMJ Open Examining LGBTI+ inclusive sexual health education from the perspective of both youth and facilitators: a systematic review
}

\author{
Muire O'Farrell (D , ${ }^{1}$ Phil Corcoran, ${ }^{1}$ Martin P Davoren ${ }^{1,2}$
}

To cite: $0^{\prime}$ Farrell M, Corcoran P, Davoren MP. Examining LGBTI+ inclusive sexual health education from the perspective of both youth and facilitators: a systematic review. BMJ Open 2021;11:e047856. doi:10.1136/ bmjopen-2020-047856

- Prepublication history and additional supplemental material for this paper are available online. To view these files, please visit the journal online (http://dx.doi.org/10.1136/ bmjopen-2020-047856).

Received 14 December 2020 Accepted 30 July 2021

Check for updates

(C) Author(s) (or their employer(s)) 2021. Re-use permitted under CC BY-NC. No commercial re-use. See rights and permissions. Published by BMJ.

${ }^{1}$ Health Promotion, Alliance Sexual Health Centre, Cork, Ireland

${ }^{2}$ School of Public Health, University College Cork, Cork, Ireland

Correspondence to Muire 0'Farrell;

muireofarrell@

sexualhealthcentre.com

\section{ABSTRACT}

Objectives To critically appraise and synthesise the evidence in relation to both the receipt and delivery of LGBTI + (Lesbian, Gay, Bisexual, Transgender, Intersex) inclusive sexual health education.

Design A systematic review and narrative synthesis. Data sources A systematic search of three online databases (EMBASE, PsychINF0 and SocINDEX) from January 1990 to May 2021 was conducted.

Eligibility criteria Studies included were (1) peerreviewed; (2) English; (3) quantitative, qualitative and mixed methods; that evaluated (4) inclusive sexual health in an educational or online setting and (5) focused on training or educating. Studies were excluded if (1) the population was not LGBTI + inclusive; (2) the studies did not focus on original data or (3) the study was not available in full text.

Data extraction and synthesis The studies that met the inclusion criteria were assessed using the Critical Appraisal Skills Programme tool. A narrative synthesis was then completed employing content analysis focusing on the results section of each article.

Results Of the 5656 records retrieved, 24 studies met the inclusion criteria. The majority of studies noted that both LGBTI+ youth and those who facilitate sexual health education are turning to online sources of information. Current sexual health education programmes operate mainly from a heterosexual perspective, creating a sense of exclusion for LGBTI+ youth. This is compounded by a lack of training, or provision of an inclusive curricula, resulting in facilitators feeling ill equipped or inhibited by their personal biases.

Conclusions LGBTI + youth are not experiencing inclusive and comprehensive sexual health education. In parallel, educators report poor access to information, training and resources remain the primary reasons. There is a need to standardise sexual health curricula, making them LGBTI + inclusive and incorporate holistic aspects of health such as pleasure and healthy relationships. Online approaches should be considered in the future, as they represent equality of access for both sexual health education professionals and LGBTI + youth alike.

\section{INTRODUCTION}

Comprehensive sexual health education has been shown to delay the onset of sexual
Strengths and limitations of this study

- The search strategy conducted used three distinct search engines to access journals with a biomedical, behavioural and sociocultural focus.

- A robust method of synthesis was employed examining both qualitative and quantitative approaches of any methodological design addressing LGBTI+ participants or educational training.

- The review includes only published, peer-reviewed studies in English and is thus susceptible to publication bias.

- It excluded grey literature (reports, conference proceedings or dissertations) and was limited to research from 1990 onwards.

- The voices of youth who identify as heterosexual and/or cisgender were not considered when determining the definition of inclusive sexuality education.

intercourse, reduce the incidence of HIV and reduce sexually transmitted infection rates among young people. ${ }^{12}$ However, this has historically been conducted from a heteronormative perspective. ${ }^{34}$ Studies have shown that early sexual experiences of LGBTI + youth are different than their heterosexual counterparts. Many frequently disengage as they feel the sexual health information delivered in schools does not directly relate to them. ${ }^{56}$

Internationally, governments and education policy makers continue to review best practice in the delivery of relationship and sexuality education (RSE).${ }^{278}$ Predominantly, the current syllabus focuses less on an individual's sexual health or sexual identity education and more on 'relationships education and marriage preparation'. ${ }^{2}$ Throughout the past decade, policy makers have considered the introduction of comprehensive, LGBTI+ inclusive RSE education with varying implementation rates worldwide. ${ }^{7}$ A recent review highlighted that the inclusion of LGBTI + faces resistance from parents, religious groups and political groups. ${ }^{7}$ In terms of 
delivery, language, the organisation ethos and the specific facilitator viewpoint and capacity have been highlighted as either enablers or barriers to effective RSE delivery.

Research indicates that when LGBTI+ sexuality is included, it can be regarded as unhelpful by LGBTI+ youthdue to a lack of appropriate LGBTI+ terminologyand sexual health-specific language relating to gender identity. ${ }^{45}$ Language is not the only barrier in discussing sexuality, same sex practices and desires. Facilitators and educators have reported feeling less confident about discussing LGBTI+ issues due to a lack of resources and training on sexual health. ${ }^{35}$ As a result, the information provided to LGBTI+ youth varies greatly across educational settings based on the facilitators' own values and comfort with the subject. ${ }^{46}$ For example, where facilitators were embarrassed to make mistakes in relation to discussing gender pronouns or explaining different genders such as non-binary, many chose not to talk about these topics at all. ${ }^{46}$

There is a need to understand best practice with regard to the delivery of inclusive sexual health education and to develop appropriate training for professionals. ${ }^{4}$ Evidence is needed to develop strategies that improve access to inclusive sexual health resources and training. The aim of this review is to critically appraise and synthesise the evidence available in relation LGBTI+ sexual health education for young people aged 16-23 years from the perspective of both the LGBTI+ youthand the professionals who deliver sexual health education in order to understand how best this can be improved.

\section{Definitions}

\section{Young people}

The term 'young people' for the purpose of this article refers to individuals aged between 16 years and 23 years. This age bracket represents the average ages for teenagers attending second and third-level education, also referred to as high school-level and college-level education, who would be in receipt of sexual health education that covers sexual identity and sexual intercourse.

\section{Facilitators}

The term 'facilitator' is used for the purpose of this article to refer to those delivering sexual health education. This encompasses teachers, educators, trainers and any form of professional who delivers sexual health education.

\section{METHODS}

\section{Search strategy}

A comprehensive literature search was conducted using the databases EMBASE, PsychINFO and SocINDEX. These databases were systematically searched for literature published between January 1990 and May 2021. This ensured a wide range of results, representative of international best practice. Each database was fully searched by MO'F and MPD using predefined search terms (see online supplemental file 1). Any discrepancy in included studies was discussed in line with the predefined inclusion criteria with a third author (PC).

\section{Study eligibility and selection}

Articles published in English between 1990 and 2021 were included in the review if they were (1) peer-reviewed journal articles; (2) related to inclusive sexual health in an educational or online setting; (3) focused on training or educating. English language content was chosen to ease assessment by a native English-speaking researcher. Peerreviewed content was employed to identify international best practice regarding sexual health training methods and educational approaches. Both quantitative and qualitative studies were included to ensure a robust representation. Publications beginning from 1990 were chosen as this tracked sexual health development following the 1988 finding that Irish Law prohibiting homosexual activities were in breach of The European Convention on Human Rights. ${ }^{9}$

Articles were excluded from the review if: (1) the population was not LGBTI+ inclusive; (2) studies were based in philosophy or theory and/or (3) the study was not available in full text (due to institution library subscriptions). Abstracts of included studies were initially abstract reviewed in line with the above criteria and articles which did not meet these criteria were deemed ineligible following inspection. The final step involved reading the full text of each article in order to identify the final group of studies to be included. A Preferred Reporting Items for Systematic Review and Meta-Analysis Protocols flow diagram presents the results in figure 1 .

\section{Quality appraisal}

In total, 24 papers were critically appraised to ascertain the alignment of the research aim and methodology, and to evaluate the recruitment, settings, data analysis, ethical issues, findings and contribution to knowledge. The individual studies were assessed for quality using the Critical Appraisal Skills Programme (CASP) tool ${ }^{10}$ (table 1).

\section{Data synthesis}

The papers comprised qualitative and quantitative study designs. There was a large degree of heterogeneity between included studies, a number of which were single prepost test in design. It is not appropriate to conduct meta-analysis on studies that are at risk of bias or are too diverse, as the results can be misleading. ${ }^{11}$ As such a narrative synthesis technique was employed, using the framework by Popay et al. ${ }^{12}$ Narrative synthesis uses words and text to summarise and explore data from both quantitative and qualitative studies. Recommendations were followed about using specified search methods and organising the output as a synthesis, to 'tell a story'. The results sections of each paper were analysed by all three authors to identify evidence of the impact of sexual health education in a variety of contexts. First, a preliminary synthesis was developed. The same relevant data were extracted from all papers and tabulated. A content analysis with an inductive 


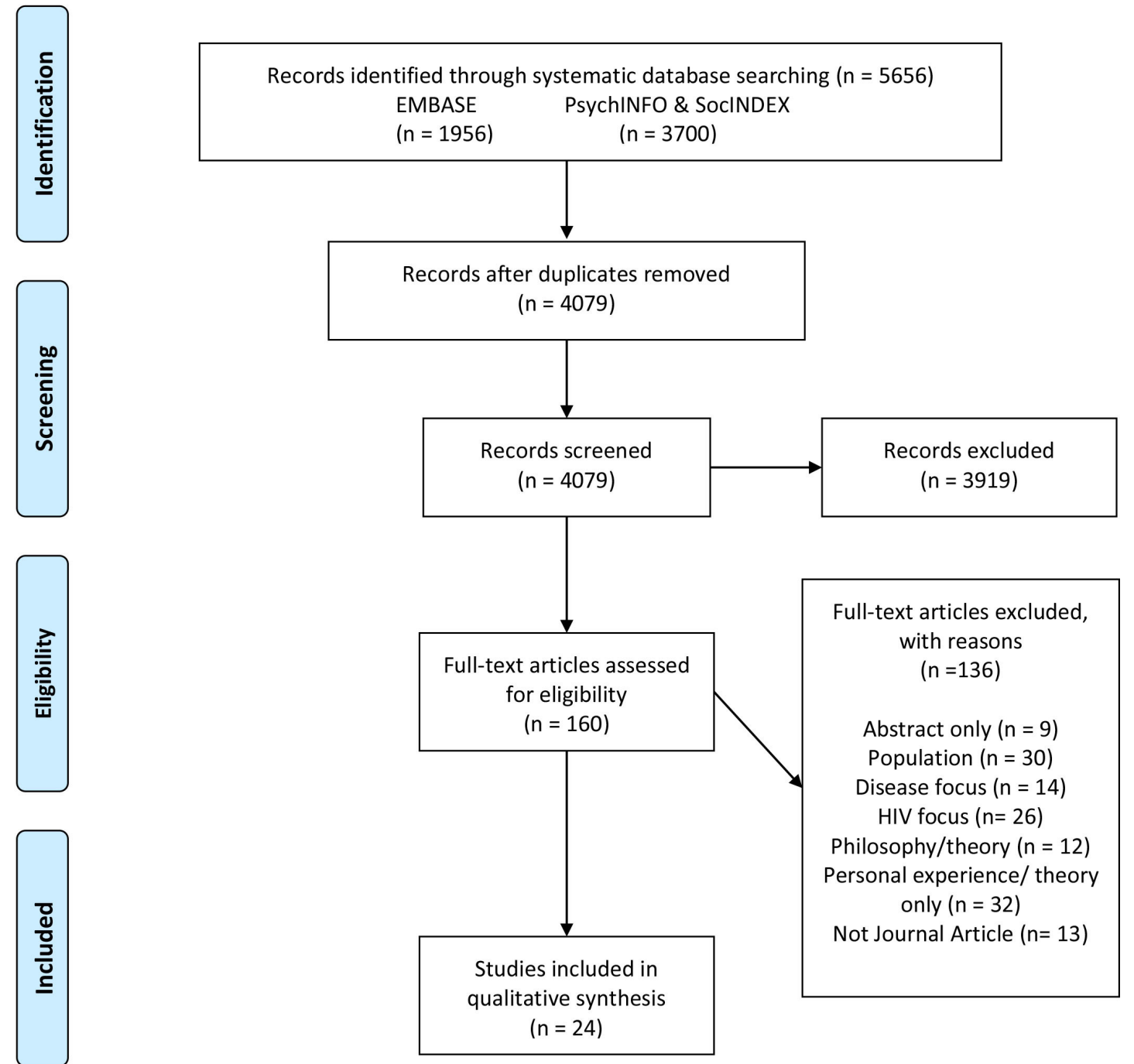

Figure 1 Identification of studies included in the review. Article selection (Preferred Reporting Items for Systematic Review and Meta-Analysis Protocols) flow diagram.

approach was then conducted which allows themes to emerge from the data (table 2). Two coauthors (MO'F and MPD) proposed and defined categories following analysis. Any discrepancies were discussed with a third author (PC).

In order to establish trustworthiness in the analysis, well-grounded methods, including thick description of the findings and maintaining a detailed audit trail were used by all three researchers. The narratives were read once before coding began for the researchers to familiarise themselves with the data. The researchers then coded the results section of each paper before these codes were grouped and summarised. These codes were then compared across authors and the relationship between codes were considered, in some cases leading to the amalgamation of separate categories under a superordinate group. Note that counting was not routinely applied in analysis, as a count is considered to convey that all codes warrant equal weighting. ${ }^{13}$

\section{Patient and public involvement}

Patients and the public were not involved or required for the completion of this study.

\section{RESULTS}

\section{Study descriptions}

The final 24 studies included 12 qualitative studies, ${ }^{14-25}$ 3 quantitative, ${ }^{26-28} 7$ mixed methods study designs ${ }^{29-35}$ and 2 reviews. ${ }^{36}{ }^{37}$ Fifteen of these focused on the experiences of LGBTI+ youth in various educational settings. ${ }^{16-18} 21$ 23-25 27-29 31 32 34-37 One referred to youth of all sexualities including heterosexual. ${ }^{22}$ Four examined professional experiences of delivering sexual health education. ${ }^{14152223}$ One examined the impact of abstinence only sexual health education, ${ }^{16}$ one examined the content of reproductive and sexual health web sites for sexual and gender minority youth ${ }^{37}$ and one examined sexual health online interventions in a men who have sex with men (MSM) chatroom. ${ }^{33}$ Three main categories were derived from the content analysis: (1) online learning, (2) inclusive programme components and (3) facilitator attributes.

Online learning to facilitate accessible equitable sexual health education

The virtual world enables instant access to information at the touch of a button. Educators and youth alike were 


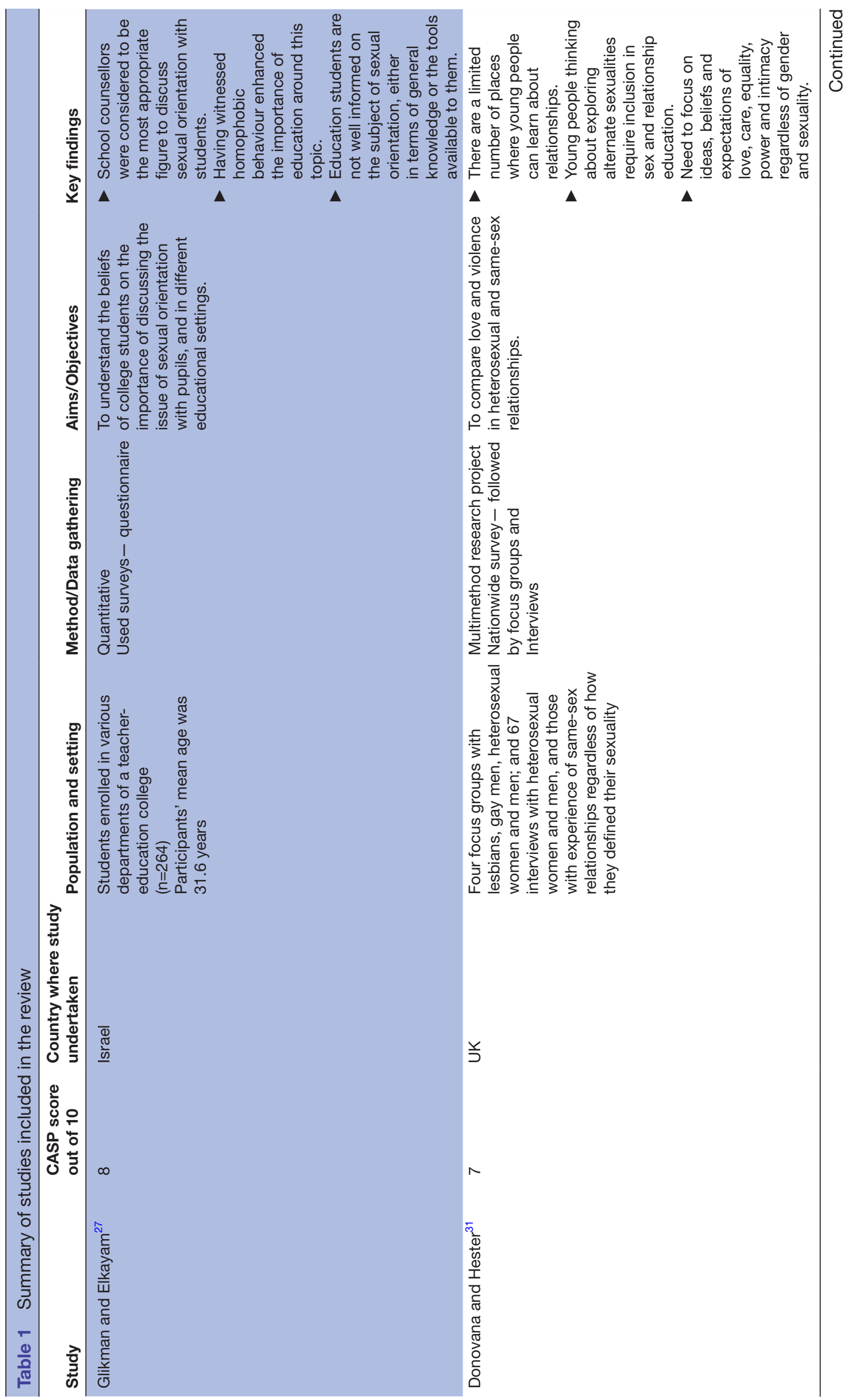




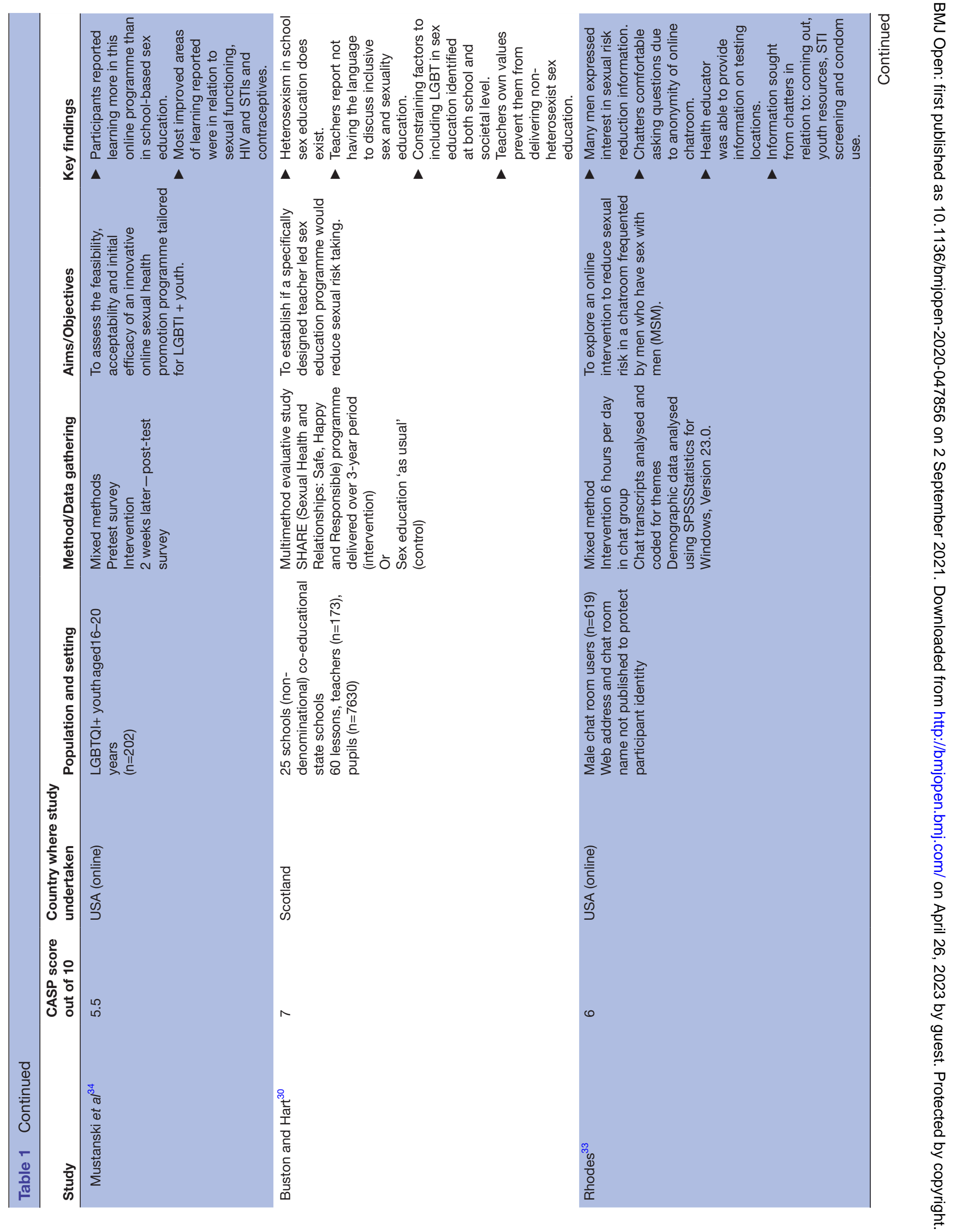




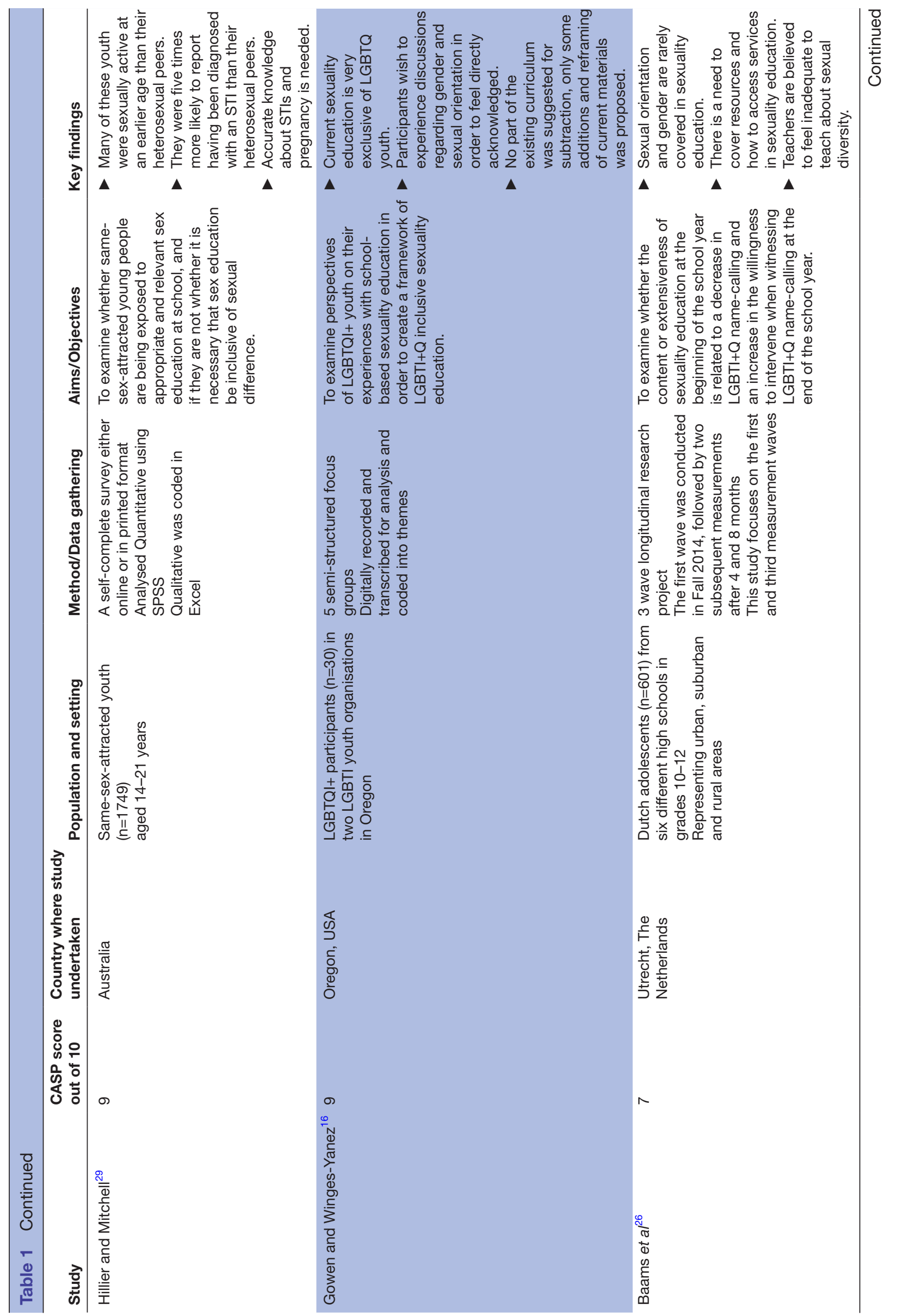




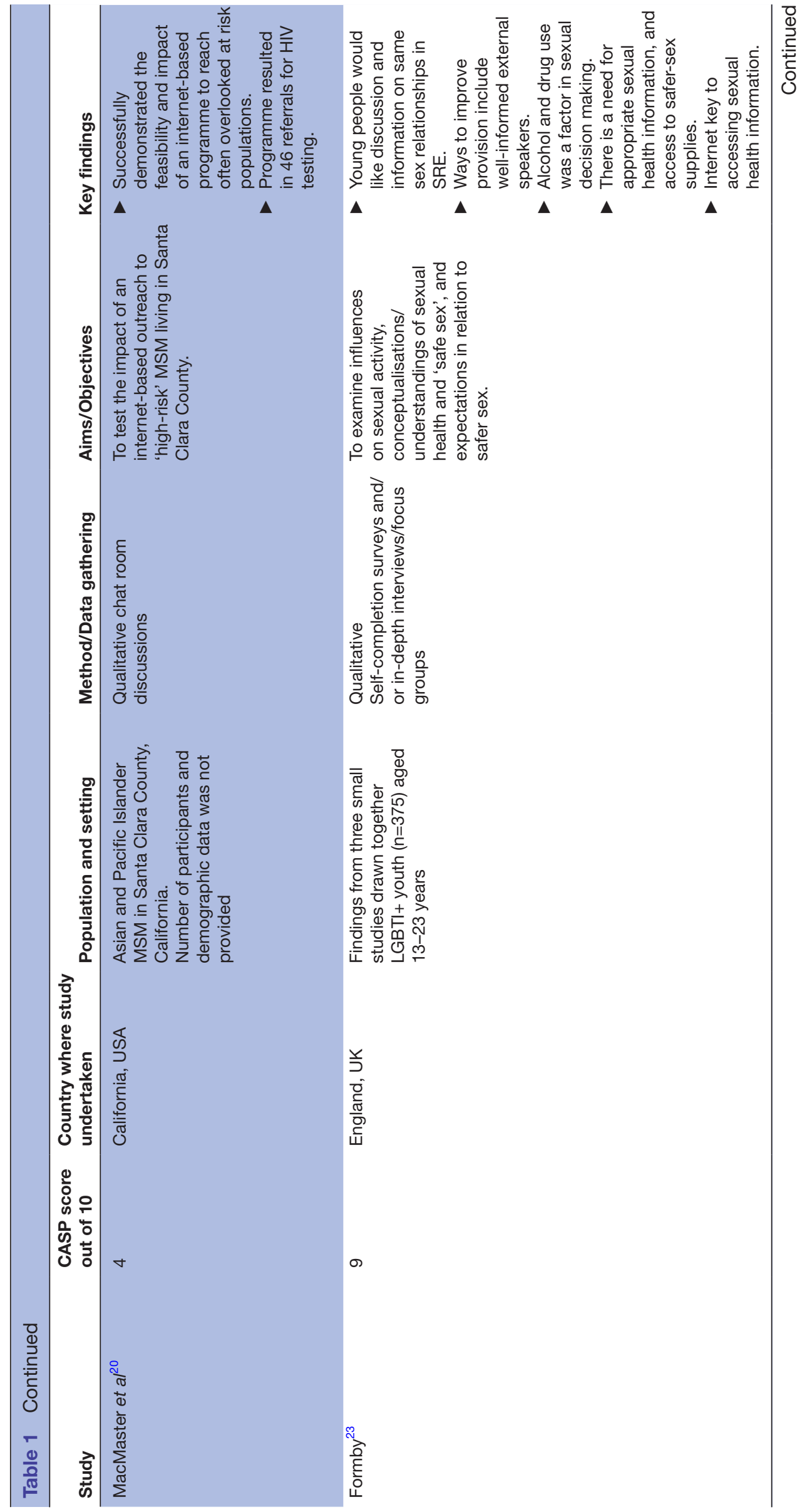




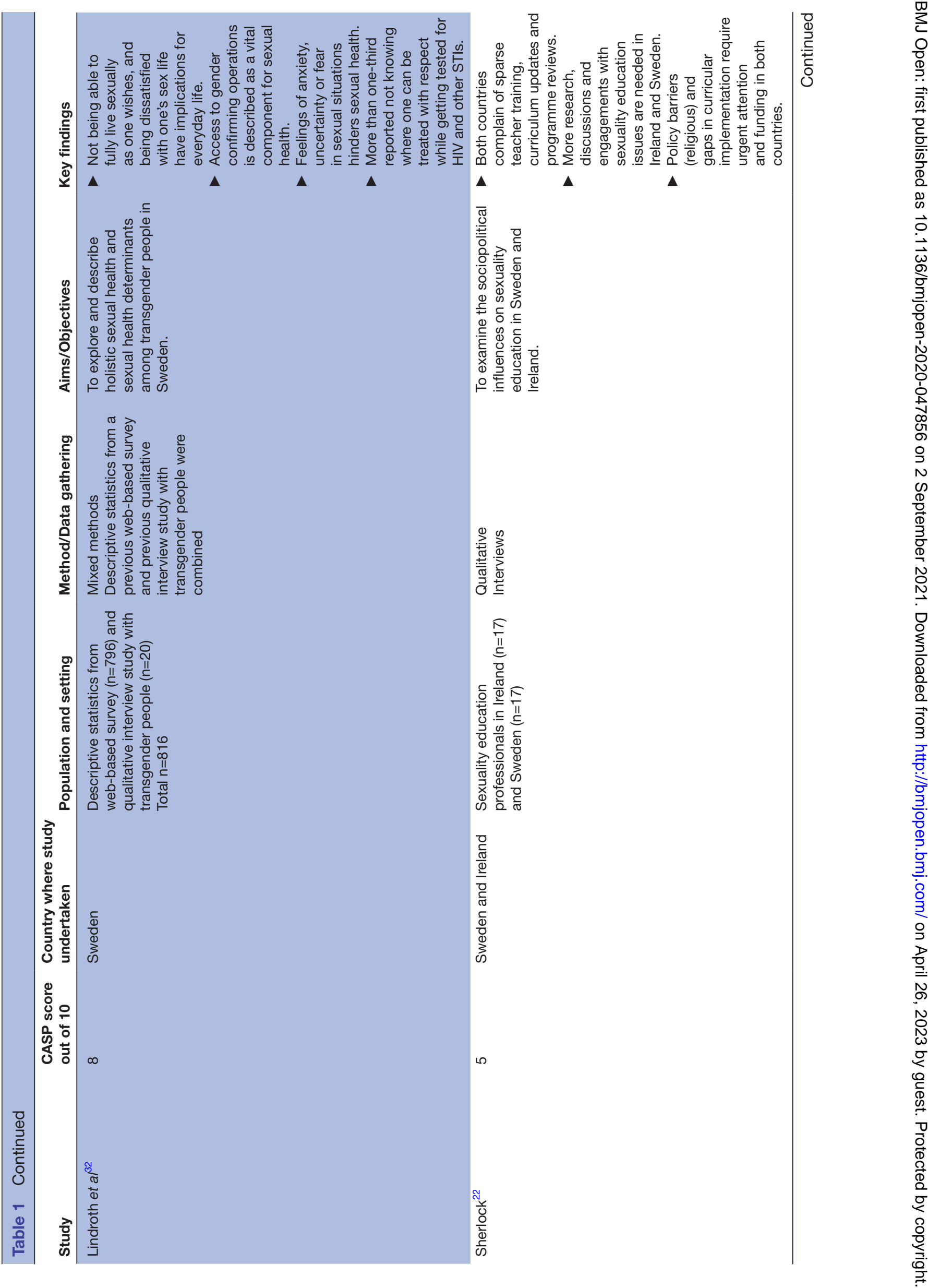




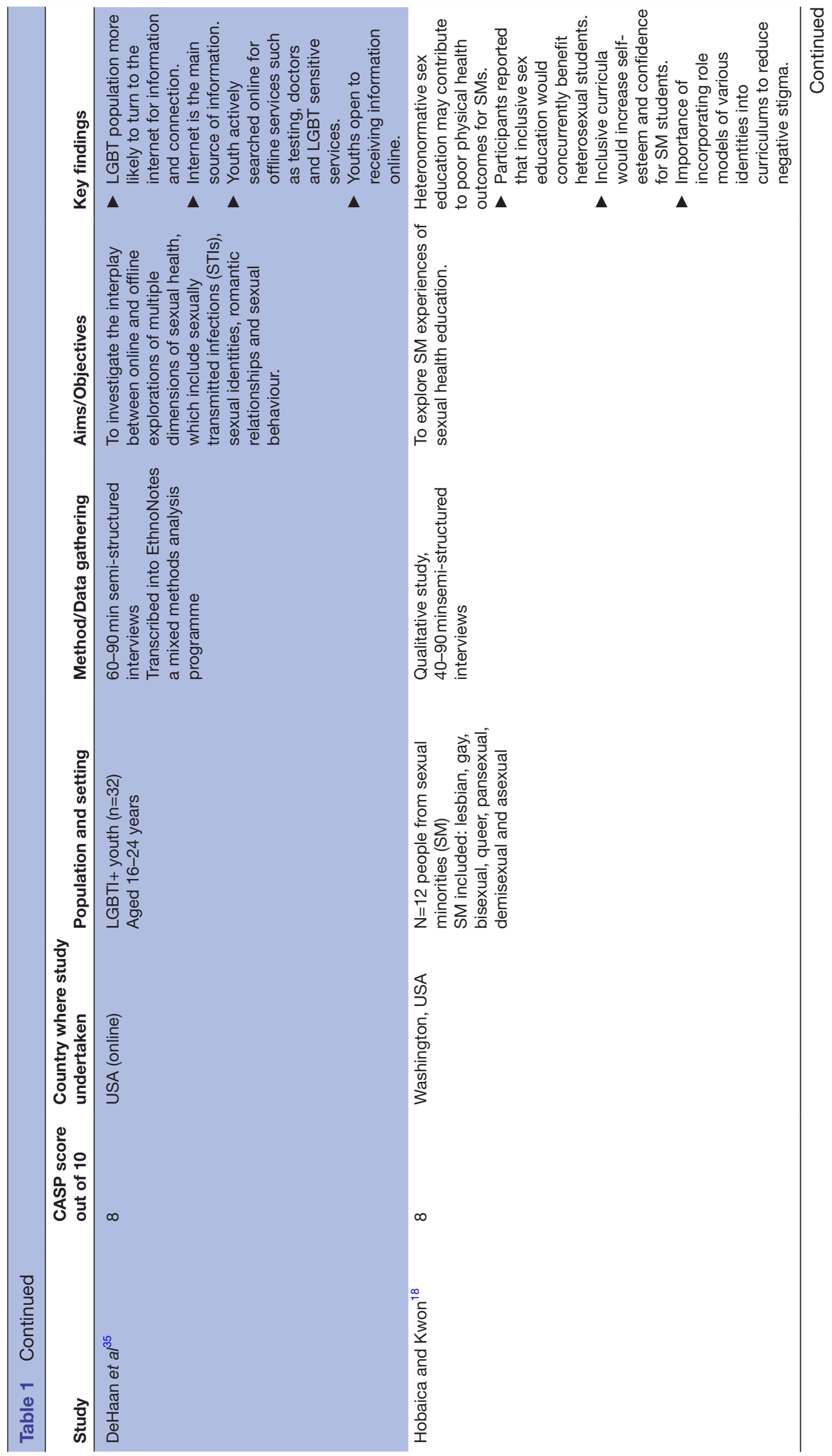




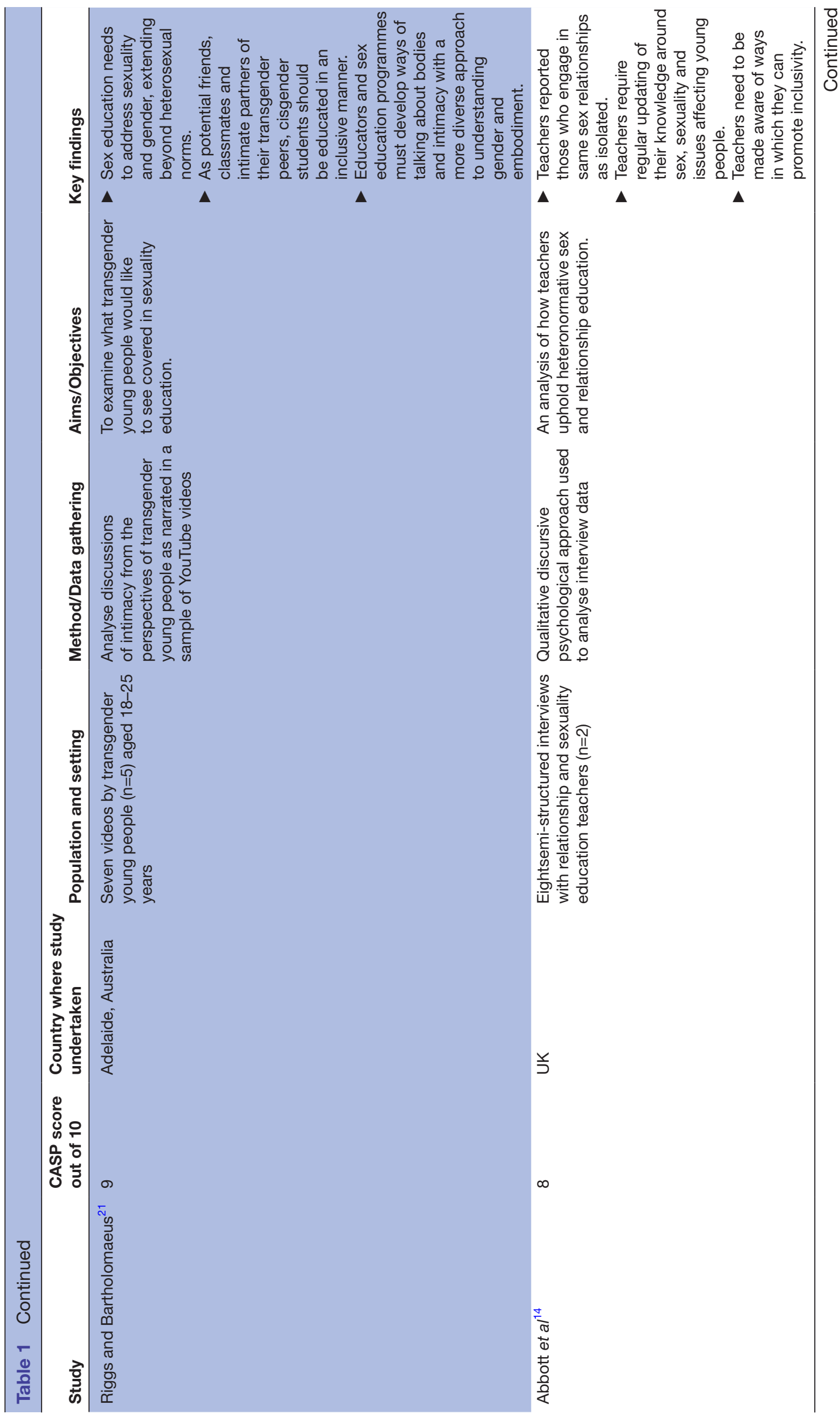

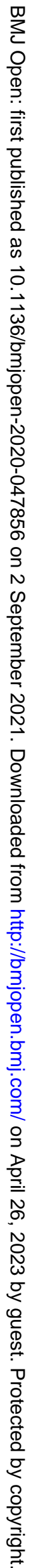




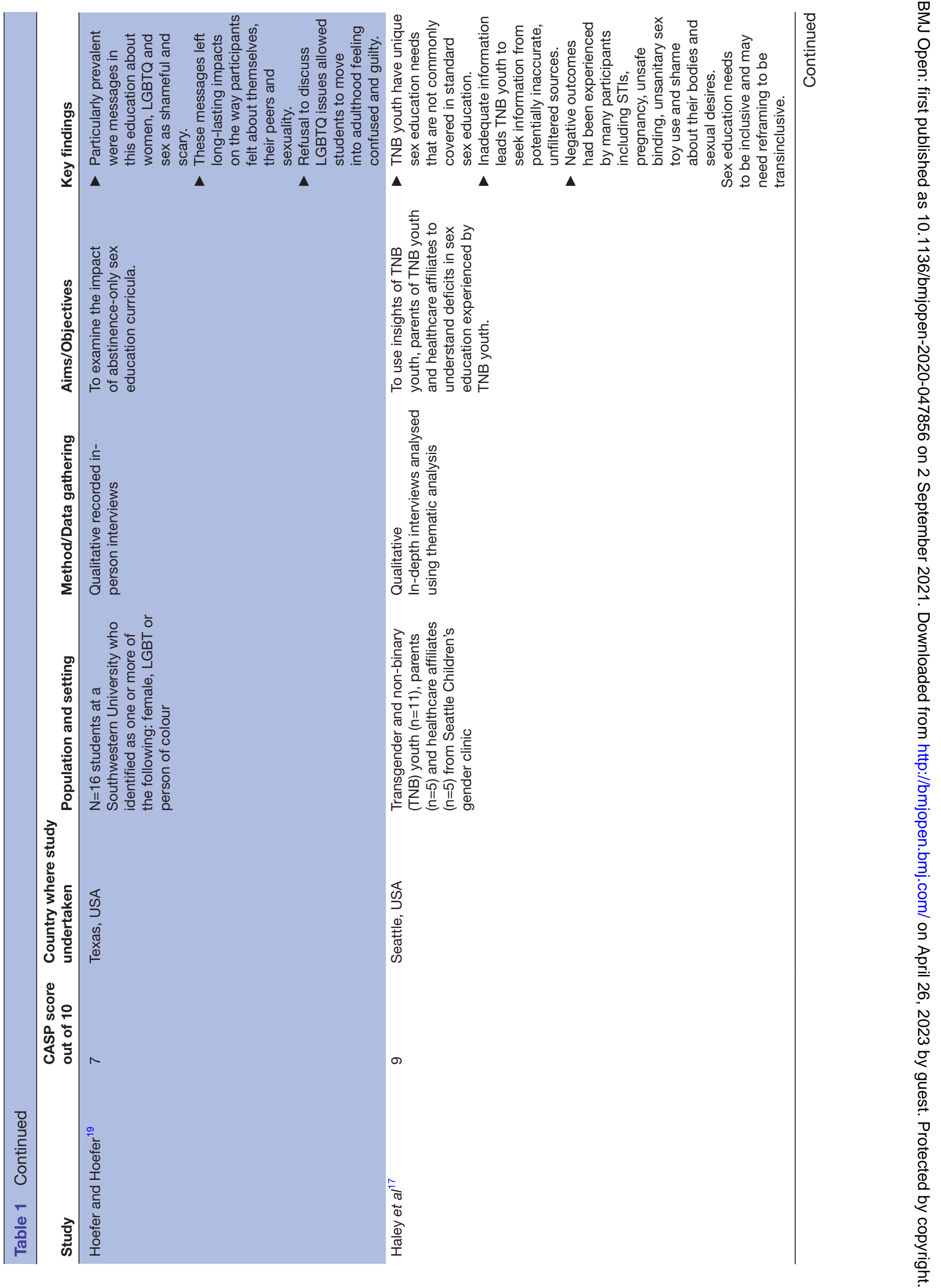




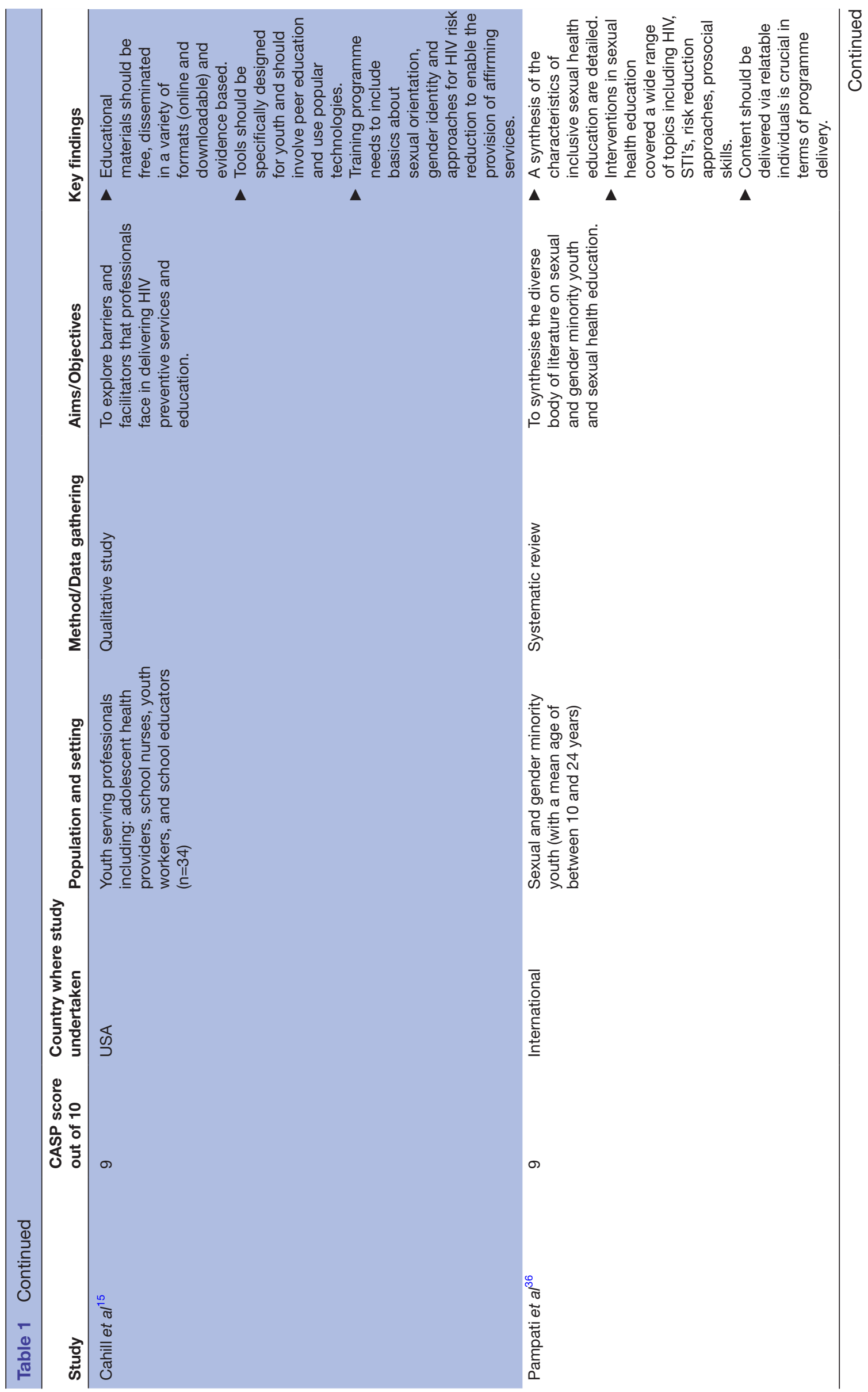




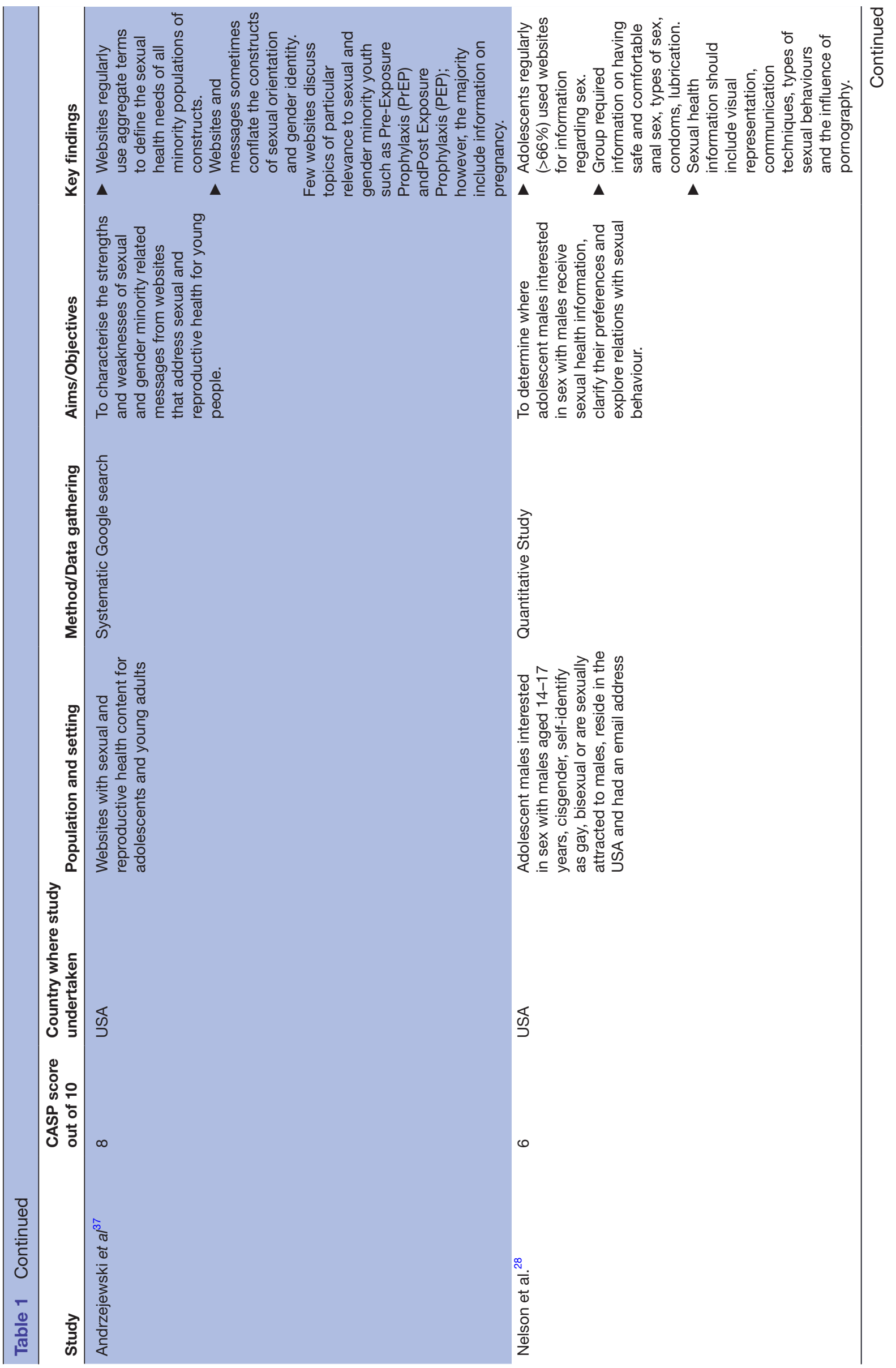




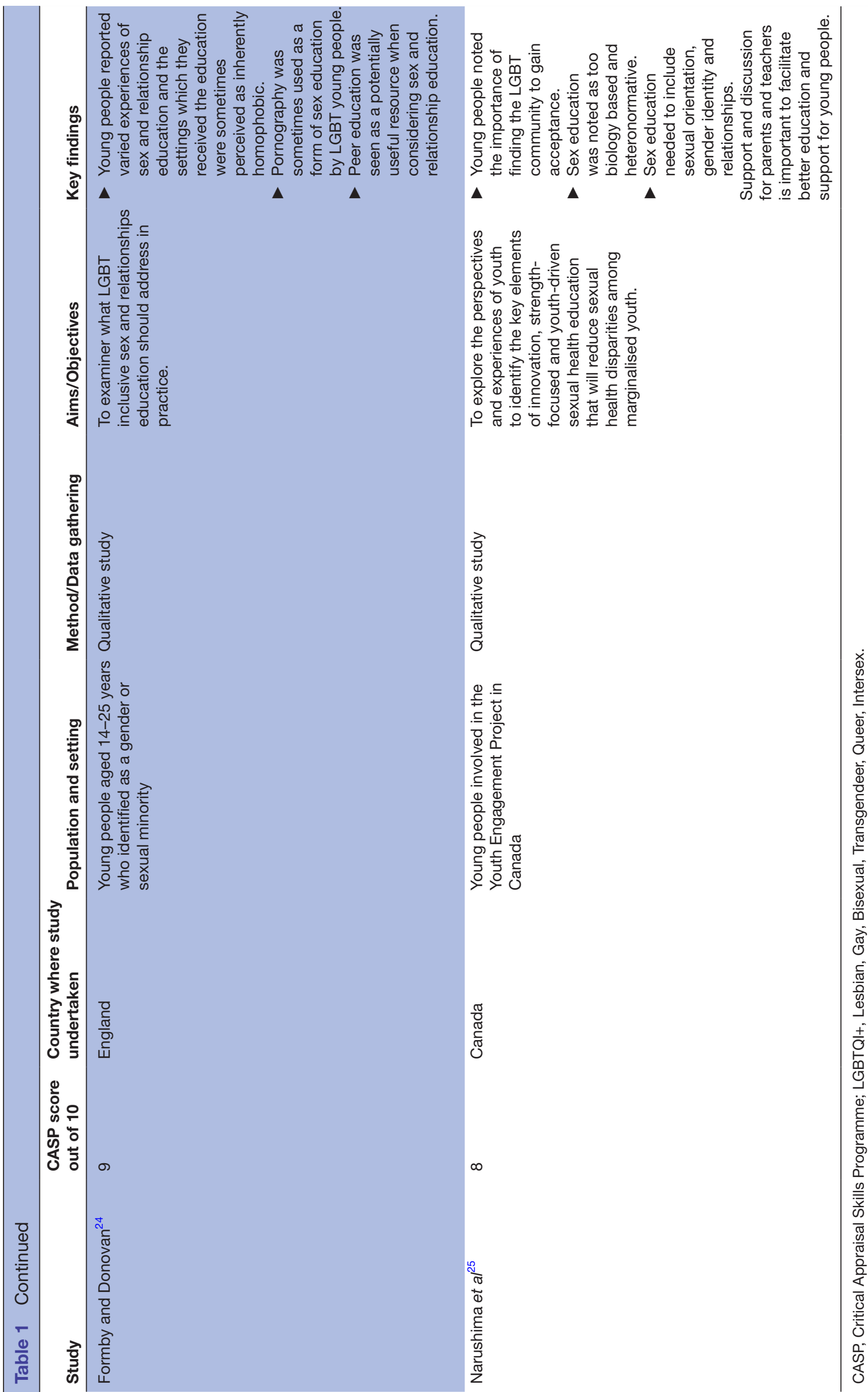




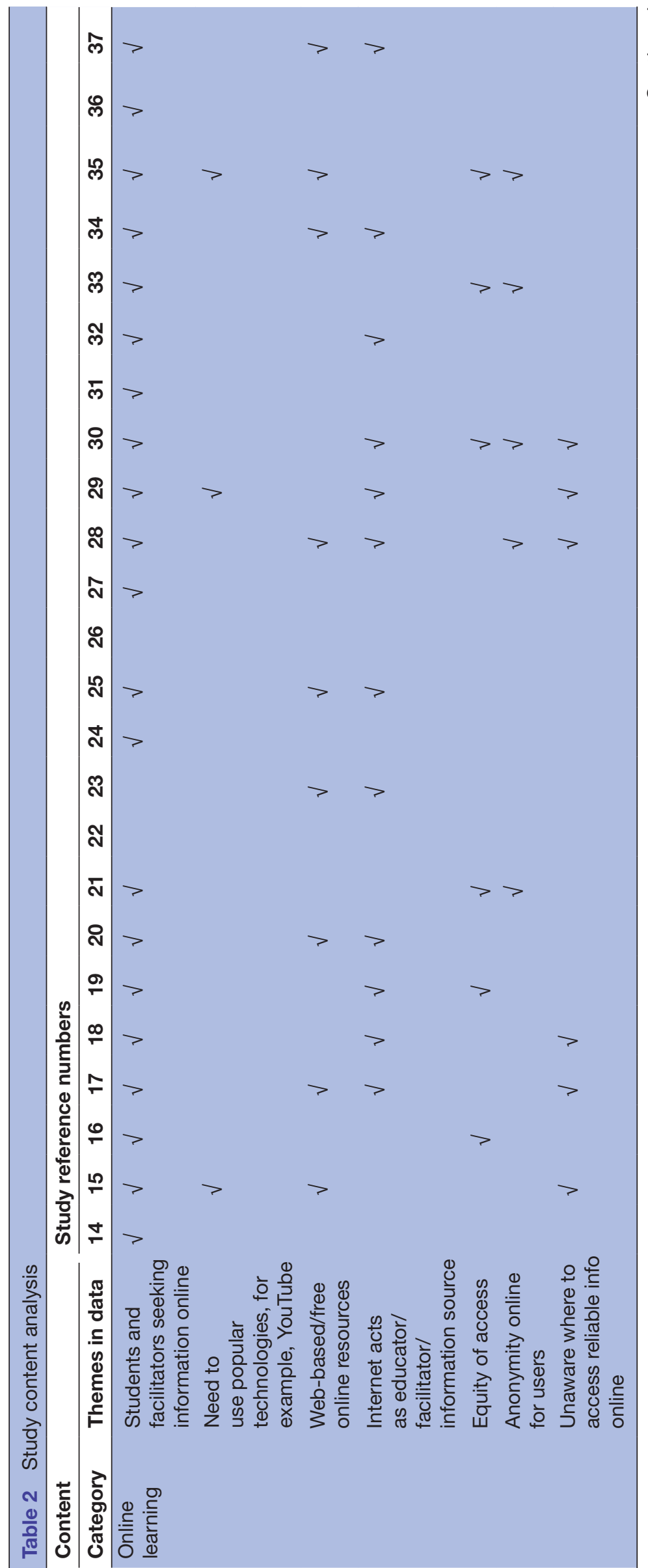

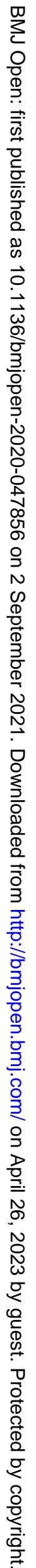




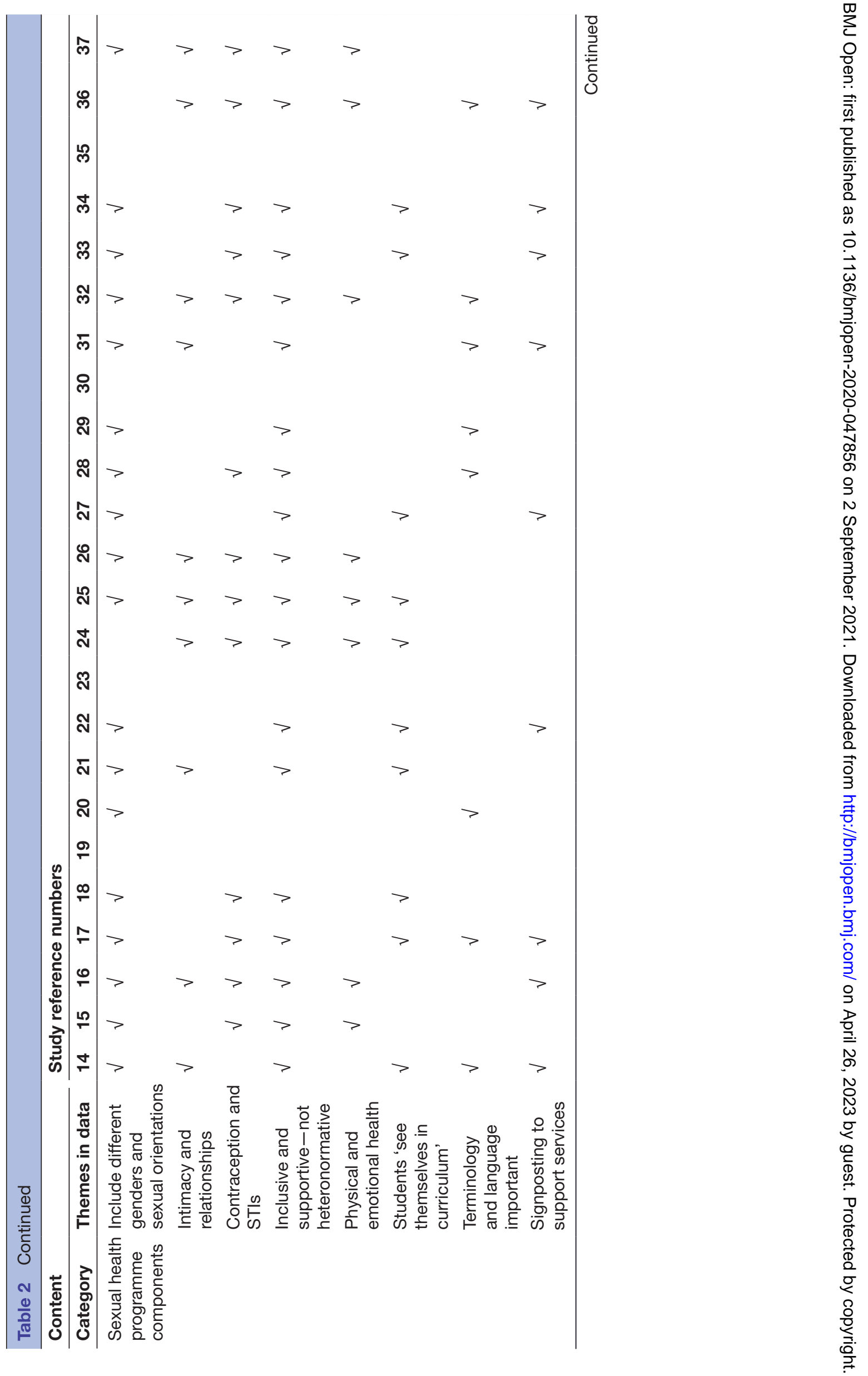




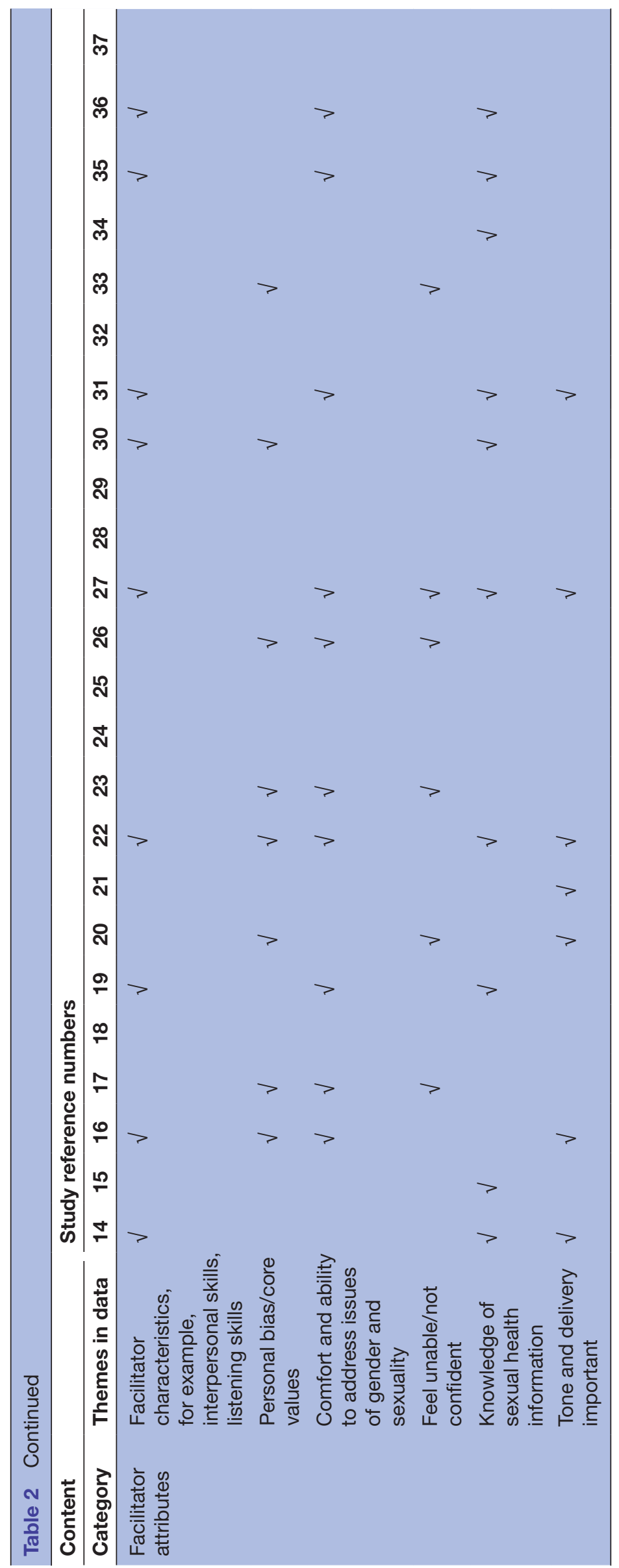


shown to be turning to online resources to seek out and access information on sexual health. Fifteen studies showed that young people are seeking sexual health information. ${ }^{14-2124272930323435}$ Of particular note was the fact that young people are open to receiving information virtually, are familiar in engaging with online platforms and are shown to learn effectively through this medium. . ${ }^{14} 16-21232831-35$

LGBTI+ youth recognising themselves in the education provided For LGBTI+ youth online access to information represents equality of access. Online sexual health information was shown to afford LGBTI+ youth control over their sexual health needs, allowing them to self-educate on topics not covered in traditional heterosexual focused sexual health education such as gender identities, sexualities and surgical and non-surgical interventions for transgender individuals. ${ }^{17}$ Specifically, LGBTI+ youth were shown to turn to the internet due to the value they place on their anonymity. ${ }^{17} 1820213034$ This was described as being of significant importance for youth who report not seeking answers in group settings for fear of being inadvertently 'outed'. 171929

While many LGBTI+ youth reported viewing the Internet as their main source of information in relation to sexual health, relationships and sexuality (Hillier), they were also shown to actively search online for a diverse range of offline services, including HIV and STI screening, where to purchase contraceptives and LGBTI+ friendly services. ${ }^{141617202127}$ The ability to access sexual health information online was shown to result in increased sexual and emotional well-being for LGBTI+ youth, ${ }^{35}$ who report poorer levels of sexual health education and higher levels of dissatisfaction with their sex lives. ${ }^{32} 33$

Internet-based sexual health education provide accessible and equitable sexual health outcomes for LGBTI+ youth, and seven studies outlined the benefit of online education as a means of accessing difficult-to-reach and overlooked populations such as those in rural or remote locations. ${ }^{16-18} 203335$ Another advantage of an online platform was the ability to interact with young people in real time. Where a chatroom-based intervention was offered, this uniquely allowed tailored messages to be provided to meet the specific needs of the young people. ${ }^{33}$ Some disadvantages were also noted such as the ambiguity for LGBTI+ youth on the best source of accurate, information online. ${ }^{30}$

\section{Facilitators having the capacity to deliver inclusive, accurate} education

Thirteen studies found that facilitators were also seeking information and training tools online due to the lack of LGBTI+ inclusive information, resources and training in the sexual health curriculums. ${ }^{14-18} 2023$ 32-35 They reported a need for web-based and downloadable teaching resources, with the suggestion that sexual health websites have links to offline materials and supports. ${ }^{15} 161920$ 33-35 There was a lack of awareness on the part of facilitators as to the best sources of information online, with an emphasis placed on the need to be able to download and transfer these resources to the education setting. ${ }^{16} 203334$ Akin to LGBTI+ youth, facilitators also highlighted the need for trustworthy resources and online sources of information online, suggesting the need for a one stop website for all sexual health enquiries and training. ${ }^{15} 162034$

\section{Online learning as a mode of inclusive learning}

The majority $(n=13)$ of the studies concluded that online learning was both possible and highly effective. ${ }^{14} 15$ 18-20 23242728323335 The results demonstrated the feasibility and potential impact of internet learning when consideration is given to a number of factors including internet connection, and that accuracy/bias of the source. ${ }^{17}{ }^{34}$ In fact, LGBTI + students in particular were shown to learn more from online than in school. ${ }^{15} 16$ 18-20 $242733-35$

In order for online learning to be as effective as possible a number of design elements were highlighted across the studies. The visual attractiveness of online platform was noted as important as it was key to engaging users and relaying the information. ${ }^{23}$ Nine studies referenced the need for an online site to provide links to offline materials and supports, along with free resources disseminated in a variety of formats such as downloadable. ${ }^{15} 161820-232635$ Two studies suggested using existing sites used by LGBTI+ youth such as YouTube, as a way of offering information online that would reach specified groups, providing them with accessible and equitable access to information. ${ }^{152535}$ However, two studies noted caution surrounding online sexual health education due to the propensity of some to use pornography as a form of education tool. ${ }^{24} 25$

\section{The programme components of inclusive sexual health education}

Overall, LGBTI+ youth reported dissatisfaction with the information included in sexual health education curriculums. The nature of sexual health education reported by participants across studies was predominantly heteronormative. ${ }^{14-22}$ 29-31 34

\section{Current relationship and sexual health education components}

Current sexual health education focused on vaginal intercourse, pregnancy prevention and marriage. As a result, many LGBTI+ youth reported they felt the course material was not relevant to their lives. Sexual diversity in terms of sexuality, same sex relationships, and identity were not included in the majority of sexual health education topics, ${ }^{141622-26313235}$ with restrictions described on topics such as sexual pleasure and what constitutes 'healthy' relationships. ${ }^{32}$ Participants across studies described sexual health education as only focusing on the biological standpoint and lacking context. ${ }^{1632}$ This resulted in LGBTI+ youth feeling vulnerable, unaccepted and 'less than' their heterosexual peers. ${ }^{1822} 2426$

Current sexual health education was also reported to focus on a medical and/or disease prevention 
methodology. ${ }^{20} 32$ While the majority of respondents across surveys reported the importance of receiving sufficient information to protect themselves against HIV and STIs, ${ }^{16} 18222326272931$ 35-37 transgender respondents in particular were unaware of services they could access where they would be treated with respect and understanding while getting an STI screening. ${ }^{16} 2332$ Four studies found that young people were not given basic information about their bodies, reproduction or contraceptives, ${ }^{171923} 32$ with some being advised to use condoms without ever being shown how. ${ }^{19} 32$

A common theme across studies related to LGBTI + invisibility, marginalisation or exclusion. ${ }^{14} 16202223303334$ Where LGBTI+ youth sought to be informed on relevant issues, they were reportedly met with what they described as 'homophobia', whereby facilitators failed to signpost LGBTI+ youth to relevant services or community groups. ${ }^{14} 1620$ 22-24 30-34 As such, many LGBTI+ youth described feeling isolated and ashamed of their sexuality and unaware of where to seek support and often reduced their engagement in any sexual health education. ${ }^{17202328303234}$

The assumption that all youth are heterosexual immediately separates the information as not personally relevant for many same-sex attracted young people, resulting in their disengagement. ${ }^{16232829}$ Three of the studies found that LGBTI + young people were unable to transfer the information they needed from classes on safe heterosexual sex to their own practice. ${ }^{162329}$ Notably, this was not the case in reverse, whereby heterosexual youth remained engaged when sexual health information was delivered in an inclusive format. ${ }^{19326}$ In fact, the inclusion of LGBTI + topics in sexual health education was shown to reduce stigma, foster self-esteem and limit negative mental health outcomes for LGBTI+ youth. ${ }^{14} 16172334$

\section{Components required for inclusivity}

The programme components required for inclusive sexual health education were discussed across studies. Sixteen studies found that sexual health education needs to encompass more than sex, puberty and pregnancy information. ${ }^{14-20} 2326 \quad 2729-34$ Topics identified for inclusion into LGBTI+ inclusive sexual health included same sex relationships, LGBTI + terminology, aspects of LGBTI + questioningand signposting to services. ${ }^{14} 16-20$ 25-30 36 There is also a need to provide information regarding sexual orientation, gender identity and approaches for STIs, ${ }^{15} 1920252930343637$ barrier protection methods ${ }^{16} 1821-232831$ and HIV risk reduction. ${ }^{16} 21223336$ Twelve studies proposed that physical and emotional aspects of sexual health need to be discussed with young people to provide a holistic approach to sexual health education. ${ }^{14-1821-2325262932343637}$ This would include discussing relationships, love and communication and creating awareness around feelings of anxiety and uncertainty. ${ }^{14-19232528343637}$ In order to promote inclusivity, the use of resources representing sexual diversity in the classroom was considered paramount. ${ }^{14} 17-2022232627$ 29-34 36
Four studies indicated that youth who experienced education on respectful intimate relations were validated in who they were and reported an overall positive effect on their sexual health experiences. ${ }^{16} 192331$ LGBTI + young people were shown to have increased well-being as a result of seeing themselves in the curriculum. ${ }^{18223236}$ Some studies identified the need to distance the discussion of relationships from gender and heterosexuality, and instead focus on beliefs, expectations of love, care equality and intimacy, regardless of gender. ${ }^{15}$ 17-19 2331 In addition, six studies found that transgender youth needed more in-depth information around gender affirming interventions both medical and non-medical, for example, binding and 'bottom surgery' (this is a form of gender affirmation surgery). ${ }^{1423303234}$

Thirteen studies reported that the tools employed for inclusive sexual health education should involve peer education, resources with youth representation and popular technologies. ${ }^{14-18} 20$ 23-25 33-35 To improve the provision of services, 15 studies pointed to the need for well-informed external speakers or educational resources. ${ }^{15-19}$ 21-23 26 29-33 35 These studies also addressed the need for education materials to be evidence based, free and disseminated in a variety of formats, including online. ${ }^{1622}{ }^{31-35}$ Six studies elucidated the importance of taking account of learning styles and promoted learning in different ways such as role playing, discussion and watching videos. ${ }^{16} 20-2326$ Three studies addressed the need to discuss what is perceived as important by youths in smaller groups. ${ }^{16} 2021$ These also highlighted the benefit of mixed groups where applicable to allow for the integration of all genders and sexualities. ${ }^{16} 2021$

In order to build capacity, the need for practical demonstrations and communication around condoms to reduce risky decision making was considered of particular importance. ${ }^{1416171923313234}$ Approaches across eight studies identified common multidisciplinary needs and identified ways to equip professionals to deliver effective sexual health education. ${ }^{14} 16172123313435$ In particular, they noted the need for the implementation of policies to reduce sexual health disparities, and the introduction of a standardised curriculum whereby professionals are equipped with appropriate knowledge relating to sexual health. ${ }^{17} 21-233134$

\section{Defining the facilitator attributes necessary for inclusive learning}

Personal values, comfort levels and access to information and training can impact on facilitator ability to deliver inclusive sexual health education. In a school context, educators were reported as crucial in creating an inclusive environment and in setting the tone for the way discussions are held. ${ }^{14151921-23262736}$ Current facilitators often complained of sparse teacher training, and lack of curriculum updates for their poor knowledge and comfort levels in relation to delivering comprehensive sexual health education, ${ }^{15-2326} 2730$ with this argument used by some to justify a need for external facilitators. ${ }^{1721} 27$ 


\section{Attributes which act as a barrier to learning}

A large percentage of studies found facilitators were ill equipped to talk about sexual health with young people due to their own discomfort with the subject matter combined with a lack of training. 1417212227293032 Particular attributes were identified as being unhelpful in the delivery of inclusive sexual health information. These included a lack of appropriate LGBTI + languageand terminology, which was shown to reinforce heteronormalising practice. ${ }^{14152132}$ Facilitators were also shown to mainly deliver sexual health from a binary perspective (male and female) excluding some LGBTI+ youth including nonbinary and intersex communities. Studies highlighted the need for facilitators to develop an approach to speaking about bodies that used gender neutral or re-gendered language. ${ }^{142132}$ They suggested that this language encompass sexually transmitted infections and pregnancy due to dysphoria experienced by some LGBTI+ youth who do not see their genitals as vagina or penis. ${ }^{21} 32$

There was also a reported ambivalence and anxiety on the part of some facilitators to deliver inclusive sexual health due to their own inherent stigma or perceived inability to address such topics due to lack of information and training. ${ }^{29} 31$ In fact, training and lack of information/resources to help in the delivery of sexual health was the main reason identified by facilitators as to why they felt unable and ill equipped to deliver LGBTI+ inclusive sexual health education. ${ }^{1417-192135}$

\section{Enabling attributes of youth education in sexual health}

The positive attributes and skills used by facilitators that were seen as beneficial to the delivery of sexual health education were also discussed. These included interpersonal skills, listening skills, acceptance and the ability to provide emotional support. ${ }^{192023262931}$ Some facilitators reported applying existing skills such as listening, containment and acceptance when trying to conduct sexual health workshops as this was not provided to them in terms of sexual health training. The tone and manner used to deliver sexual health was also noted as important in how it is received by young people. Facilitators who appeared comfortable with the subject matter and used a steady, confident and warm tone were regarded as most effective in their delivery of sexual health information. ${ }^{1521}$

The ability to appear approachable and knowledgeable of same sex relationships was also considered an important attribute, as LGBTI+ youth linked these with the facilitators ability to validate same sex relationships and different gender identities. ${ }^{161926272930}$ In particular, interpersonal skills such as the ability to listen and accept were highlighted as most beneficial as these enabled the facilitator to build capacity in both themselves and young people by demonstrating openness and acceptance of others, and adapting to new information and ways of thinking. ${ }^{14} 18-213235$

Differing attributes among facilitators can severely impact on a young person's experience of sexual health education. This variation in experience is highlighted across studies in the need for standardised sexual health policies and curriculums. ${ }^{15} 20-23263035$ Those tasked with the delivery of sexual health education programmes require training and upskilling of their knowledge on sex, sexuality and LGBTI +-specific sexual health information, and training to promote better interpersonal and listening skills. ${ }^{14151719-212330}$ This would enable facilitators to deliver an inclusive curriculum in a supportive environment that takes account of young people's varying sexual identities, relationships and sexual health needs. ${ }^{1415172122273035}$

\section{DISCUSSION}

Sexual health is an important aspect of overall health. ${ }^{38}$ Therefore, inclusive and comprehensive sexual health information should be accessible to all. This review provided a clear overview of the nature of sexual health education as it exists currently. In the absence of inclusive, standardised sexual health education, both young people and facilitators are turning to online platforms to access information and resources. Sexual health education programmes need to be re-designed for the successful delivery of LGBTI+ inclusive sexual health education and the attributes that can impact facilitator delivery need to be considered and addressed.

These findings add to the growing picture of LGBTI+ youth experiences of sexual health, and the constructed heterosexual culture created by education providers and society at large. The former is characterised by high levels of invisibility and marginalisation prominent in LGBTI+ youth accounts of schooling. ${ }^{1617232629}$ Previous research notes how 'sex education is one very effective way in which the heteronormative status quo is maintained'. 39 Sex education has remained stagnant throughout the past number of decades despite liberation of many peripheral areas. This has led 'to criticism of inclusivity, morals and ethics and other criticism; however, it has yet to become all-inclusive, comprehensive and effective'. ${ }^{39}$ This is compounded by inadequate information offered to youths, often associated with staff attitudes/behaviours or insufficient training. ${ }^{14-1629}$ Throughout this synthesis, both youth and facilitators noted the internet as their main source of information about LGBTI + sexual health and services. $^{14-19212330-35}$ This is complimented by findings of Magee $e t$ al, which suggest that LGBTI+ youth often turn to the internet for relevant sexual health information. ${ }^{40}$ Given the lack of comprehensive, LGBTI+-relevant sexual health information available to these youths, the internet represents a crucial, yet underdeveloped setting to provide this information. These findings highlight the need for the provision of evidence-based, inclusive, online resources for youth to safely and securely access accurate sexual health information. This would represent equality of access for all young people enabling them to access inclusive information from any location and at any time of their choosing. Equally online training for facilitators would enable direct and standardised training of all 
those providing sexual health education, and the ability for updated information to reach those delivering in an effective manner.

The need for sexual health education to extend beyond heterosexual norms was also paramount across the studies included in this synthesis. Facilitators and sexual health education programmes must develop ways of talking about bodies and intimacy that shift attention away from the normative association of particular genders with particular anatomies, to encompass a more diverse approach to understanding gender and embodiment in order to make an inclusive programme for all. This can be seen in the curricula in New Zealand, where gender is not discussed as binary, and gender identities and diversity are explored. ${ }^{41}$ The studies examined called for inclusive sexual education, inclusive of information on condoms, relationships and communication. ${ }^{14-19}$ 21-23 $262730-3234$ In addition, previous research highlights that the inclusion of LGBTI + issues has positive effects on all sexualities. ${ }^{7}$ Previous research has shown this type of education increases healthy sexual behaviour in the general student population. ${ }^{2}{ }^{41-51}$ It is possible therefore that similar behaviour changes could be expected for LGBTI+ youth with the introduction of a comparable LGBTI+ inclusive sexual health programme.

The results of this synthesis also demonstrate that facilitators differ in their ability to deliver inclusive sexual health due to a lack of knowledge and personal values/ beliefs in relation to sexual diversity. ${ }^{14-19} 23262729303435$ The main obstruction reported was access to training and resources. This is in keeping with findings from the Netherlands which found that school programmes do not provide supportive and affirming messages, and educators feel ill equipped to address LGBTI+ topics. ${ }^{50}$ As far back as 2008, Kirby demonstrated comprehensive sexual health had significant effects on delaying initiation of sex and increasing condom and contraceptive use. ${ }^{48}$ As such it is crucial that inclusive, comprehensive sexual health education be available to both students and facilitators and that sexual health curriculums are designed to standardise this for all young people.

Overall, this synthesis demonstrated that sexual health education needs to encompass more than sex, puberty and pregnancy. ${ }^{14-19}$ 21-23 27 29-31 34 This supports previous research findings that all students require applicable, informative sexual health education, and that inclusive information is acceptable to all, unlike heteronormative education. ${ }^{52}$ As the virtual world we live in becomes the new norm for teaching and training, it appears clear that sexual health education needs to adapt in terms of content and in terms of delivery. The lack of inclusive sexual health education in school settings can only be addressed if those who are facilitating these programmes are trained and provided with the appropriate resources to do so. In order to do this, the internet appears to be the most obvious platform for both educators and youths to access information. Therefore, online platforms should be used by policy makers to train, educate and offer resources for the LGBTI+ community along with those who are responsible for the delivery of this education such as teachers and facilitators.

The findings of this review signal the requirement for sexual health policy and educational bodies to standardise an LGBTI+ inclusive curriculum for young people, ensuring facilitators are provided with adequate training and upskilling to deliver it effectively and that this training and information is made accessible on a secure, national platform. ${ }^{14-19} 2335$ These findings also have implications for practice, whereby the means by which sexual health education training is accessed by professionals will be fully online, removing any disparities between rural and central locations. ${ }^{20} 2633$ This will also enable those accessing training to do so at times suitable to their individual schedules and feel confident in their ability to access information at any time from a reliable source as required.

Further research is needed to better understand the ability of online training to address the need for inclusive sexual health education. Such research should examine the types of platforms sexual health information is delivered on, and how these are advertised, in order to reduce equality of access and information for young people and professionals. Research is also required in relation to the ability of online training to address the disparities that result due to negative facilitator attributes. Such research would help to further standardised inclusive sexual health education across school settings, reduce stigma and foster inclusion for LGBTI+ young people in the school environment.

\section{Strengths and limitations}

This review gives a broad overview of best practice in relation to sexual health education for LGBTI+ youth. A search strategy was conducted using three different search engines to access journals with a varying biomedical, behavioural and sociocultural focus. A robust method of synthesis was employed examining both qualitative and quantitative approaches. The resulting synthesis can be used to help guide future intervention development.

This review has a number of limitations. The inclusion of Medline as a fourth search engine, may have increased the comprehensiveness of the search. The review includes only published peer-reviewed studies in English and is thus susceptible to publication bias. Including studies of varying quality could yield misleading results.

In terms of the included studies, a number of limitations were noted. The majority did not discuss the relationship between the researcher and the participants. In addition, predefined sample size calculations were not reported in all studies. This review excluded grey literature (reports, conference proceedings or dissertations) and was limited to research from 1990 onwards. This review did not account for the use of or absence of theoretical models within sexual health education programmes and their ability to change behaviours, something that should be considered in future research. In addition, the voices 
of youth who identify as heterosexual and/or cisgender should also be considered when determining the definition of inclusive sexuality education.

\section{Conclusions}

LGBTI+ youth are currently not experiencing inclusive and comprehensive sexual health education. Poor access to information, training and resources remain the primary reasons this is not being delivered. In order to address this, future interventions would benefit from using online approaches that facilitate learning for all. Online training for sexual health education providers would offer unprecedented access to inclusive, comprehensive sexual health information removing any geographical barriers or disparities. The provision of such training online would also enable any updates to information or practice to be directly accessed by those providing sexual health education. This could more comprehensively serve the needs of both the LGBTI+ communityand those responsible for providing accurate, comprehensive sexual health education.

\section{Twitter Muire 0'Farrell @MuireFarrell}

Contributors MO'F and MPD designed the review, undertook the review searches, screened for eligibility and assessed the quality of the included studies. MO'F, MPD and $\mathrm{PC}$ completed the data analysis. MO'F prepared the draft of the systematic review, edited the draft of systematic review. MPD read and approved the final manuscript.

Funding This work was supported by the Department of Children, Equality, Disability, Integration and Youth (DCEDIY), Block 1 Miesian Plaza, 50-58 Baggot Street Lower, Dublin 2, D02 XWI4, Ireland. The DCEDIY did not have any role in the conduct or report of this review. We do not perceive there to be any conflict of interest related to their role in the reporting of this systematic review.

Competing interests All authors have completed the Unified Competing Interest form at http://www.icmje.org/coi_disclosure.pdf (available on request from the corresponding author) and declare that (1) MO'F, MPD and PC all work in the area of sexual health, delivering inclusive sexual health workshops and educational interventions to groups. (2) Funding was received from DCEDIY to pay for the research post held by MO'F.

Patient consent for publication Not required.

Ethics approval Due to the nature of this type of research, ethical approval and review was not required.

Provenance and peer review Not commissioned; externally peer reviewed.

Data availability statement Data sharing not applicable as no datasets generated and/or analysed for this study.

Supplemental material This content has been supplied by the author(s). It has not been vetted by BMJ Publishing Group Limited (BMJ) and may not have been peer-reviewed. Any opinions or recommendations discussed are solely those of the author(s) and are not endorsed by BMJ. BMJ disclaims all liability and responsibility arising from any reliance placed on the content. Where the content includes any translated material, BMJ does not warrant the accuracy and reliability of the translations (including but not limited to local regulations, clinical guidelines, terminology, drug names and drug dosages), and is not responsible for any error and/or omissions arising from translation and adaptation or otherwise.

Open access This is an open access article distributed in accordance with the Creative Commons Attribution Non Commercial (CC BY-NC 4.0) license, which permits others to distribute, remix, adapt, build upon this work non-commercially, and license their derivative works on different terms, provided the original work is properly cited, appropriate credit is given, any changes made indicated, and the use is non-commercial. See: http://creativecommons.org/licenses/by-nc/4.0/.

\section{ORCID iD}

Muire 0'Farrell http://orcid.org/0000-0001-8185-8540
REFERENCES

1 World Health Organization. Report on global sexually transmitted infection surveillance. Geneva: World Health Organization, 2018. https://www.who.int/reproductivehealth/publications/stissurveillance-2018/en/

2 Mayock P, Kitching K, Morgan M. Relationships and sexuality education (RSE) in the context of social, personal and health education (SPHE): an assessment of the challenges to full implementation of the programme in post-primary schools. Department of Education and Science, 2017.

3 Meadows E. Sexual health equity in schools: inclusive sexuality and relationship education for gender and sexual minority students. Am J Sex Educ 2018;13:297-309.

4 Schneiderman N, Speers MA, Silva JM. Integrating behavioral and social sciences with public health. Am Psych Assoc 2001.

5 Paul Poteat V, Russell ST, Dewaele A. Sexual health risk behavior disparities among male and female adolescents using identity and behavior indicators of sexual orientation. Arch Sex Behav 2019;48:1087-97.

6 Savin- Williams RC. Identity development amoung sexual minority youth. In: Schwartz SJ, Luyckz K, Vignoles V, eds. Handbook of identity theory and research. New York, NY: Springer, 2011: 671-89.

7 Gegenfurtner A, Gebhardt M. Sexuality education including lesbian, gay, bisexual, and transgender (LGBT) issues in schools. Educ Res Rev 2017;22:215-22.

8 Garg N, Volerman A. A national analysis of state policies on lesbian, gay, bisexual, transgender, and questioning/queer inclusive sex education. J Sch Health 2021;91:164-75.

9 Helfer LR. Finding a consensus on equality: the homosexual age of consent and the European convention on human rights. New York University Law Review 1990;65:1044-100.

10 Critical Appraisal Skills Programme UK. CASP checklists. Available: https://casp-uk.net/casp-tools-checklists/ [Accessed 5 Oct 2020].

11 Campbell M, Katikireddi SV, Sowden A, et al. Lack of transparency in reporting narrative synthesis of quantitative data: a methodological assessment of systematic reviews. J Clin Epidemiol 2019;105:1-9.

12 Popay J, Roberts H, Sowden A, et al. Guidance on the conduct of narrative synthesis in systematic reviews. Lancaster: ESRC Research Methods Programme, 2006.

13 Creswell JW. Qualitative inquiry and research design: choosing among five approaches. 2nd edn. Sage Publications, Inc, 2007.

14 Abbott K, Ellis S, Abbott R. "We Don't Get Into All That": An Analysis of How Teachers Uphold Heteronormative Sex and Relationship Education. J Homosex 2015;62:1638-59.

15 Cahill SRet al. Youth-serving professionals' perspectives on HIV prevention tools and strategies appropriate for adolescent gay and bisexual males and transgender youth. J Pediatric Health care 2019.

16 Gowen LK, Winges-Yanez N. Lesbian, gay, bisexual, transgender, queer, and questioning youths' perspectives of inclusive schoolbased sexuality education. J Sex Res 2014;51:788-800.

17 Haley SG, Tordoff DM, Kantor AZ, et al. Sex education for transgender and non-binary youth: previous experiences and recommended content. J Sex Med 2019;16:1834-48.

18 Hobaica S, Kwon P. "This is how you hetero:" Sexual minorities in heteronormative sex education. Am J Sex Educ 2017;12:423-50.

19 Hoefer SE, Hoefer R. Worth the wait? The consequences of abstinence-only sex education for marginalized students. Am J Sex Educ 2017;12:257-76.

20 Macmaster SA, Aquino R, Vail KA. Providing HIV education and outreach via Internet CHAT rooms to men who have sex with men. $J$ Hum Behav Soc Environ 2004;8:145-51.

21 Riggs DW, Bartholomaeus C. Transgender young people's narratives of intimacy and sexual health: implications for sexuality education. Sex Educ 2018;18:376-90.

22 Sherlock L. Sociopolitical influences on sexuality education in Sweden and Ireland. Sex Educ 2012;12:383-96.

23 Formby E. Sex and relationships education, sexual health, and lesbian, gay and bisexual sexual cultures: views from young people. Sex Educ 2011;11:255-66.

24 Formby E, Donovan C. Sex and relationships education for LGBT+ young people: lessons from UK youth work. Sexualities 2020;23:1155-78.

25 Narushima M, Wong JP-H, Li AT-W, et al. Youth perspectives on sexual health education: voices from the YEP study in Toronto. Can $J$ Hum Sex 2020;29:32-44.

26 Baams L, Dubas JS, van Aken MAG. Comprehensive sexuality education as a longitudinal predictor of LGBTQ name-calling and perceived willingness to intervene in school. $J$ Youth Adolesc 2017;46:931-42. 
27 Glikman A, Elkayam TS. Addressing the issue of sexual orientation in the classroom - attitudes of Israeli education students. J LGBT Youth 2019;16:38-61.

28 Nelson KM, Pantalone DW, Carey MP. Sexual health education for adolescent males who are interested in sex with males: an investigation of experiences, preferences, and needs. J Adolesc Health 2019:64:36-42.

29 Hillier L, Mitchell A. 'It was as useful as a chocolate kettle': sex education in the lives of same-sex-attracted young people in Australia. Sex Educ 2008;8:211-24.

30 Buston K, Hart G. Heterosexism and homophobia in Scottish school sex education: exploring the nature of the problem. J Adolesc 2001;24:95-109.

31 Donovan C, Hester M. 'Because she was my first girlfriend, I didn't know any different': making the case for mainstreaming same-sex sex/relationship education. Sex Educ 2008;8:277-87.

32 Lindroth M, Zeluf G, Mannheimer LN, et al. Sexual health among transgender people in Sweden. Int J Transgend 2017;18:318-27.

33 Rhodes SD. Hookups or health promotion? An exploratory study of a CHAT room-based HIV prevention intervention for men who have sex with men. AIDS Educ Prev 2004;16:315-27.

34 Mustanski B, Greene GJ, Ryan D, et al. Feasibility, acceptability, and initial efficacy of an online sexual health promotion program for LGBT youth: the Queer Sex Ed intervention. J Sex Res 2015;52:220-30.

35 DeHaan S, Kuper LE, Magee JC, et al. The interplay between online and offline explorations of identity, relationships, and sex: a mixedmethods study with LGBT youth. J Sex Res 2013;50:421-34.

36 Pampati S, Johns MM, Szucs LE, et al. Sexual and gender minority youth and sexual health education: a systematic mapping review of the literature. J Adoles Health 2021;68:1040-52.

37 Andrzejewski J, Rasberry CN, Mustanski B, et al. Sexual and reproductive health web sites: an analysis of content for sexual and gender minority youth. Am J Health Promot 2020;34:393-401.

38 Chin HB, Sipe TA, Elder R, et al. The effectiveness of group based comprehensive risk-reduction and abstinence education interventions to prevent or reduce the risk of adolescent pregnancy, human immunodeficiency virus, and sexually transmitted infections: two systematic reviews for the guide to community preventive services. Am J Prev Med 2012:42:272-94.
39 Sabo-Bassett D. Book review- the education of EROS: a history of education and the problem of adolescent sexuality, by Dennis L. Carlson. New York, NY: Routledge, 2021. 216. J LGBT Youth 2017;14:445-8.

40 Magee JC, Bigelow L, Dehaan S, et al. Sexual health information seeking online: a mixed-methods study among lesbian, gay, bisexual, and transgender young people. Health Educ Behav 2012;39:276-89.

41 Ministry of Education. Sexuality education: a guide for principals, board of trustees, and teachers. Wellington: Ministry of Education, 2015.

42 Rust PC. Designing a course on sexuality: Issues, problems, and parameters. Crit Sociol 1994;20:155-68.

43 Lenderyou $\mathrm{G}$. Entitlement to sex and relationship education. Child Soc 1998;12:315-7.

44 Dunlap A. Supporting youth in the coming-out process: theory-based programming. Smith Coll Stud Soc Work 2014;84:107-29.

45 Elia JP, Tokunaga J. Sexuality education: implications for health, equity, and social justice in the United States. Health Educ 2015;115:105-20.

46 Friend RA. Undoing heterosexism and homophobia: Moving from 'talking the talk' to 'walking to talk'. J Sex Educ Ther 1998;23:94-104.

47 Kirby D. Emerging answers: research findings on programs to reduce teen pregnancy. Washington DC: National Campaign to Prevent Teen Pregnancy, 2001.

48 Kirby DB. The impact of abstinence and comprehensive sex and STD/HIV education programs on adolescent sexual behavior. Sex Res Soc Policy 2008;5:18-27.

49 Humphreys T. Web sites for sexuality educators and health professionals. Canadian J Human Sex 1999;8:309.

50 Schools M-CDM. Sex education, and support for sexual minorities: exploring historic marginalization and future potential. Am J Sex Educ 2013;8:246-73.

51 Whitman JOYS. Providing training about sexual orientation in counselor education. Counselor Educ Sup 1995;35:168-76.

52 Hall WJ, Jones BLH, Witkemper KD, et al. State policy on schoolbased sex education: a content analysis focused on sexual behaviors, relationships, and identities. Am J Health Behav 2019;43:506-19 